\title{
Primary Ovarian Lymphoma: A Rare Entity
}

\section{Pandit SP ${ }^{1}$, Pandit $\mathbf{S}^{2}$, Pandit $\mathbf{S}^{3}$, Rauniyar $\mathbf{A}^{1}$}

${ }^{1}$ Department of Radiodiagnosis and Imaging, National Academy of Medical sciences, Kathmandu, Nepal

${ }^{2}$ Department of Medicine, Froedtert and the Medical College of Wisconsin, USA ${ }^{3}$ Department of Obstetrics and Gyanecology, Paropakar Womens \& Maternity hospital, Kathmandu, Nepal

Received: September 19, 2019

Accepted: October 30, 2019

Published: December 31, 2019

Cite this paper:

Pandit SP, Pandit S, Pandit S, Rauniyar A. Primary Ovarian Lymphoma: A Rare Entity. Nepalese Journal of Radiology 2019;9(14):48-51.http://dx.doi.org/10.3126/njr.v9i2.27430

\begin{abstract}
Primary ovarian lymphoma (POL) refers to involvement of the ovary with lymphoma but without the involvement of any other site. It is an extremely rare yet well-recognized condition. We present to you a case of 25 year old female who presented with abdominal distension and mild lower abdominal pain for 4 weeks diagnosed radiologically and pathologically as primary ovarian lymphoma.
\end{abstract}

Keywords: Abdominal Pain; Lymphoma; Ovarian Neoplasms

\section{INTRODUCTION}

Primary ovarian lymphoma is a rare condition of ovary, diffuse B-cell type is most common histological subtype of POL in adults \& Burkitt's lymphoma, the second common. Both are high grade, but the prognosis generally tends to be better than other primary ovarian tumors. Primary ovarian lymphoma are rare with few cases described. We describe one such rare case of primary ovarian lymphoma.

\section{CASE REPORT}

A 25 year old female presented with abdominal distension and mild lower abdominal pain for 4 weeks. Physical examination showed distended abdomen and palpable mass in pelvic cavity with features of free fluid.

Correspondence to: Dr Swoyam Pandit Liver and Spleen were normal. No history of

Department of Radiology \& Imaging

NAMS, Kathmandu, Nepal

Email-swoyampandit@hotmail.com

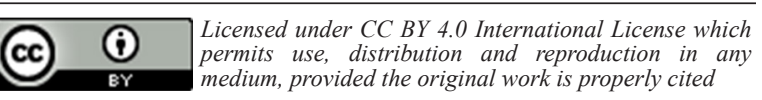


malignancy was present. Her hematological, bio-chemical and serological tests were within normal limits. Her CA 125 level was 839 U/ $\mathrm{ml}^{3}$. Serum B-HCG and Serum LDH were within normal limits. Her ultrasonography showed large $12 \times 11 \mathrm{~cm}$ size hypoechoic solid mass in right side of pelvis with moderate ascites. Computed tomography(CT) of Chest, abdomen \& pelvis was done and showed well defined moderately enhancing mass of $11.8 \times 10.7 \mathrm{~cm}$ size in right side of pelvic cavity with retroperitoneal lymph nodes and ascites. Chest was normal. No other mass lesions were seen in any other site. Peripheral blood smear and Bone marrow examination were normal. Cerebro-spinal fluid (CSF) study was normal. CT pelvis showed large well defined moderately enhancing mass in right ovary with encasement of right gonadal vessels (Figure 1) and displaced multiple cysts in peripheral aspect of mass in right ovary (Figure 2) \& hence diagnosis of malignant right ovarian mass likely Germ cell tumor was made. Left ovary was normal. Ultrasonography showed large hypoechoic solid mass in right adnexa with ascites (Figure 3). Patient refused surgery and underwent cytology for ascitic fluid which showed features suspicious for Lymphoma and then USG guided true cut biopsy was done from the mass. The pathological diagnosis was primary ovarian Lymphomadiffuse large B-cell type (Figure 4). Immunohistochemistry (IHC) showed diffuse large B-cell lymphoma, non-germinal center subtype. The patient received chemotherapy (Doxorubicin, Vincristin, Cyclophosphamide, Rituximab, and Lenalidomide) and on 15 months period of follow up, no recurrence was observed. Moderate free fluid was noted in peritoneal cavity. No hepatosplenomegaly was evident. No other masses were detected in chest, abdomen and pelvic region. MRI was not performed.

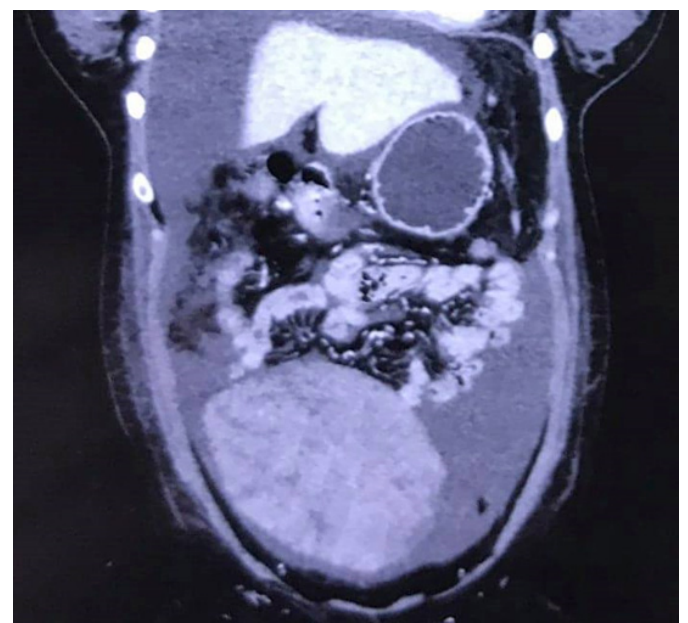

Figure 1: Coronal contrast enhanced CT abdomen \& pelvis shows Large moderately enhancing soft tissue density mass in right ovary encasing gonadal vessels. Moderate ascites.

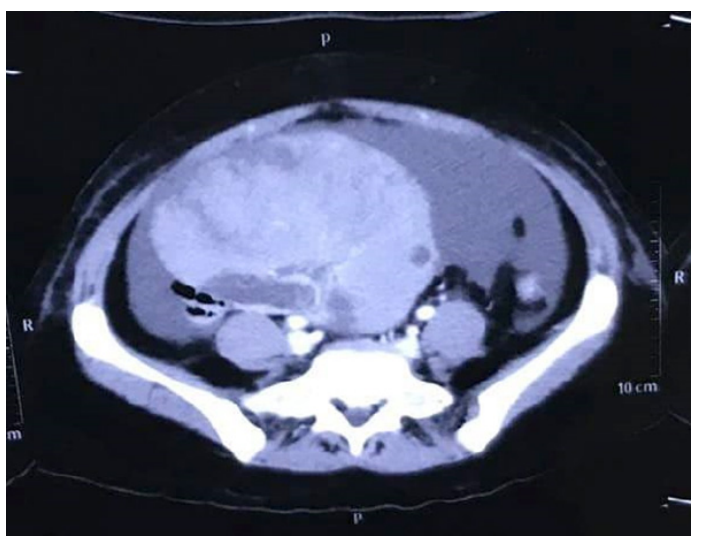

Figure 2: Axial contrast enhanced CT pelvis shows large right ovarian mass with displaced multiple small cysts in periphery. 


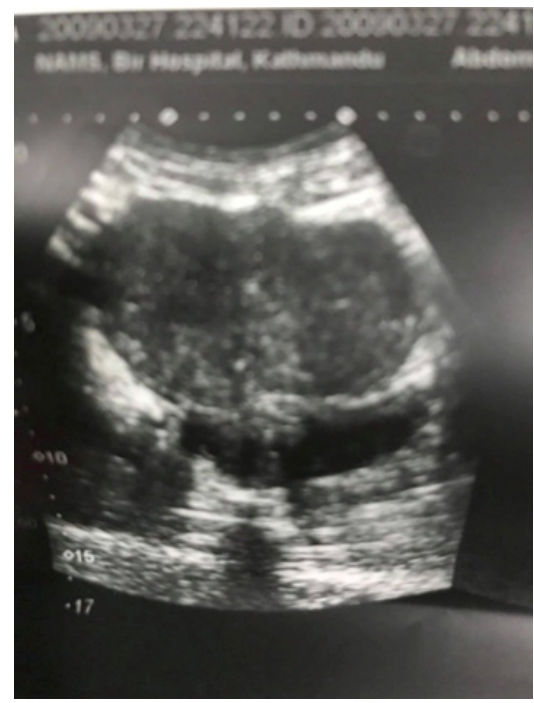

Figure 3: USG-Large hypo echoic solid mass in right adnexa with ascites.

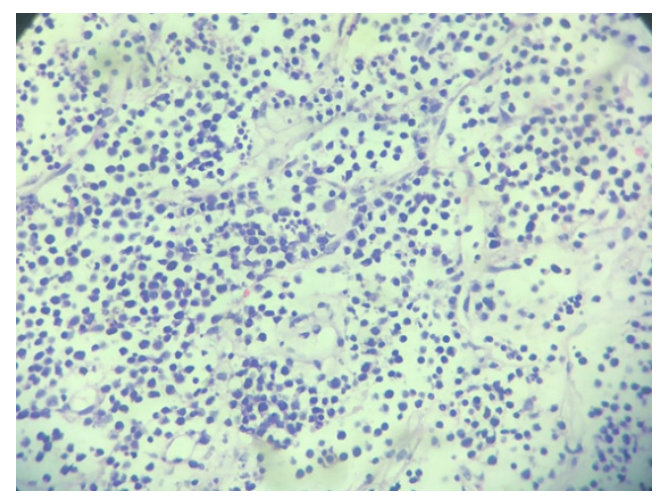

Figure 4: Pathology report: Section shows diffuse proliferation of small to medium sized lymphocytes with scanty cytoplasm, irregular nucleoli and mitotic figures.

\section{DISCUSSION}

In Primary Ovarian Lymphoma (POL) there is involvement of ovary without the involvement of any other site of body. It is extremely rare condition and accounts for $0.5 \%$ of NHL and $1.5 \%$ of all ovarian tumors. ${ }^{1}$ The ovaries don't have lymphoid tissue, so tumor origin is probably from lymphocytes of adjacent blood vessels. $^{2}$ In almost all cases, non-Hodgkin lymphoma (NHL) with diffuse B-cell type is the commonest type, followed by Burkitt's lymphoma.

Chein $\mathrm{JC}$ et $\mathrm{al}^{3}{ }^{3}$ in their study on primary ovarian lymphoma reported CA-125 level of $1366 \mathrm{U} / \mathrm{ml}^{3} \&$ mean level of $1111 \mathrm{U} / \mathrm{ml}^{3}$ but in our case, it is in lower side $839 \mathrm{U} / \mathrm{ml}^{3}$.

This is a rare case with non-specific findings, hence Radiologists should be aware of this diagnosis. Lymphoma can involve the ovary, and when involved, it is usually bilateral, most common is Non-Hodgkin's lymphoma followed by Burkitt's lymphoma. ${ }^{4}$ Most of them require no extensive surgical staging \& treatment involves that of the lymphoma. ${ }^{5}$

The pathology of ovarian neoplasm is one of the most complex areas of gynecology, because the ovary gives rise to a greater range and variety of tumors than any other part of human organ while in other organs the tissue of origin is usually clear. ${ }^{6}$

The main treatment of POL is Surgery with chemotherapy but this patient refused surgery and underwent Chemotherapy. On follow up study after 15 months, no mass was seen. Crawshaw $\mathrm{J}$ et al. ${ }^{2}$ showed POL managed by chemotherapy alone and dramatic reduction of the mass by 6 weeks period.

Criteria for diagnosis of POL- according to FOX $\mathrm{H}$ et al. ${ }^{7}$

1. The lymphoma is clinically in the ovary and in full investigation fails to reveal lymphoma in any other parts of body.

2. The peripheral blood smear and bone marrow study should be negative.

3. If further lymphomatous lesion occurs in any part other than ovary, then at least several months should have elapsed between the ovarian lesion and extraovarian lesions.

Ferrozziet $\mathrm{F}$ et al. ${ }^{8}$ described the radiological features of primary ovarian Lymphoma (POL), CT-Hypodense lesion with minimal enhancement but done for staging purpose. This is one of the rare condition, FIGO staging is not established and NHL staging system is used.

Sonography shows usually hypoechoic solid lesion which is non specific. ${ }^{9} \mathrm{CT}$ is imaging modality of choice for ongoing assessment, particularly for staging and follow up. CT 
often shows low attenuation with minimal enhancement. MRI shows homogenous signal T1W- hypo intense, T2W- minimal hyperintense mass.

\section{CONCLUSION}

Primary ovarian lymphoma is a rare condition of ovary, diffuse B-cell type is most common histological subtype of POL in adults and Burkitt's lymphoma, the second common. Both are high grade, but the prognosis generally tends to be better than other primary ovarian tumors. Ovarian tumor with a central infiltrating growth pattern, normal architecture and cyst in periphery are typical features of primary ovarian lymphoma. None of these finding are found in metastasis or ovarian carcinoma. The other key point is encasement of gonadal vessels passing through the hilum, forming sandwich sign.

Thus, POL should be considered in the differential diagnosis, especially when there is encasement of gonadal vessels and displacement of cyst in the periphery of mass without involvement of other organs.

\section{CONFLICT OF INTEREST}

None

\section{SOURCES OF FUNDING}

None

\section{REFERENCES}

1. Dimopoulos MA, Daliani D, Pugh W et al. Primary ovarian non-Hodgkin's lymphoma: outcome after treatment with combination chemotherapy. Gynecol Oncol 1997;64(3):446-450. https://doi. org/10.1006/gyno.1996.4583

2. Crawshaw J, Sohaib SA, Wotherspoon A, Shepherd JH. Primary non-Hodgkin's lymphoma of the ovaries: imaging findings. Br J Radiol 2007;80(956):e155158.https://doi.org/10.1259/bjr/35049074

3. Chien JC, Chen CL, Chan WP. Case 210:
Primary ovarian lymphoma. Radiology 2014;273(1):306-309. https://doi. org/10.1148/radiol.14121326

4. Afshan A, Sadaf N. Primary ovarian lymphoma--a rare entity. J Pak Med Assoc. 2013 A;63(4):519-20. Jeffcoate's Principle of gynecology, Ovarian neoplasm 8th edition 2014: 492-493. https://www.ncbi. nlm.nih.gov/pubmed/23905454

5. Jonathan S. Berek \& Novan's Gynecology - text book of Gynecology, Ovarian cancer 15th edition 2018:1413-1414.

6. Jeffcoate's Principle of gynecology, Ovarian neoplasm 8th edition 2014:492493.

7. Fox H, Langley FA, Govan AD, Hill AS, Bennett MH. Malignant lymphoma presenting as an ovarian tumour: a clinicopathological analysis of 34 cases. BJOG: An International Journal of Obstetrics \& Gynaecology. 1988;95(4):386-390. https://doi. org/10.1111/j.1471-0528.1988.tb06611.x

8. Ferrozzi F, Catanese C, Uccelli M, Bassi P. Ovarian lymphoma. Findings with ultrasonography, computerized tomography and magnetic resonance. $\mathrm{La}$ Radiologia medica 1998;95(5):493-497. Available from: https://www.ncbi.nlm. nih.gov/pubmed/9687927 [Accessed 5th August 2019].

9. Glick Y, Weerakkody Y. Primary ovarian lymphoma case presentation. Available from: $\quad$ https://radiopaedia.org/articles/ primary-ovarian-lymphoma [Accessed 16th August 2019]. 